\title{
The Chemical Performance Evaluation for Pour Point Depressant (PPD) Testing, X Oil Field, Vietnam
}

\author{
Ngoc Thai Ba ${ }^{1}$, Cuong Nguyen Lam Quoc ${ }^{2}$ \\ ${ }^{1,2}$ Ho Chi Minh City University of Technology
}

\begin{abstract}
Pour Point Depressant (PPD) Testing are used extensively to modify the crystallinity of hard waxes and to reduce the natural pour point of crude. The best PPD chemical and best dosage for crude oil treatment will be chosen based on the laboratory test results to: Reduce pour point of crude oil; Reduce viscosity of crude oil; Improve rheological properties of crude oil; Reduce wax deposition rate and pipeline restart pressure.

The chemical performance evaluation for PPD, proposed to use at X Oil Field has been conducted in Crude oil and Petroleum products Lab. The following properties have been determined in laboratory for blank sample (which is a mixture of H1, H4 and H5 crude oil samples with ratio of 2.1:1.4:1.0) and sample treated by PPD (rundown crude oil sample): Pour Point (for blank sample and treated sample); Wax Appearance Temperature (WAT) and Wax Disappearance Temperature (WDT) (for blank sample); Dynamic Viscosity (for blank and treated samples); Yield Stress by Rheometer (for blank and treated samples) for 100 mins, 1000 mins and 02 days shut-in times; Wax Deposition Rate by Cold Finger for blank and treated samples; Restart Pressure by Restart Loop (for blank and treated samples) for 100 mins, 1000 mins and 02 days shut-in times.
\end{abstract}

KEYWORDS: Pour Point Depressant (PPD) Testing, Blank and Treated sample, Wax Appearance Temperature (WAT) and Wax Disappearance Temperature (WDT), Dynamic Viscosity, Wax Deposition.

\section{INTRODUCTION}

\section{Wax Deposition and Gelation}

Wax deposition and gelation are two risks in crude oil systems: the deposition of n-paraffin will commonly occur along the pipe walls when the temperature of produced fluids falls below the Wax Appearance Temperature (WAT); wax gelation is a common concern during production system shutdowns and during restart operations. To review the potential for wax deposition and gelation, together with available provided data, the Wax Appearance Temperature (WAT), the Wax Disappearance Temperature (WDT), Pour Point of crude, Wax Deposition Tests by Cold-Finger of the crude oil should be evaluated.

\section{Wax Deposition Rate}

A knowledge of wax deposition rate in pipeline under dynamic cooling condition is essential in an effect to prevent or mitigate wax deposition in a pipeline. Test can be performed in the laboratory to provide information pertaining to wax deposition rate. Measurement of wax deposition rate can be done under dynamic condition. A cold finger tube is immersed in an oil bath held at a temperature of $10 \mathrm{oC}$ above the cold finger tube temperature or the cold finger tube's temperature can be set at the sea bed temperature to observe the behaviours of wax deposition process.

\section{Crude oil and crude oil emulsion rheology}

Rheology describes the deformation of a body under the influence of stress. Viscometry deals specifically with the measurement of flow behaviour of liquids as a function of pressure, temperature, shear rate and shear duration.

For waxy crude, rheological studies are usually tailored by assessing the degree of wax crystallisation that occurs during cooling process of the crude and the effect of wax crystallisation depended on the shear rate dependent dynamic viscosity and wax deposition tendency of the crude. Viscometry measurements are made using a Haake rotational viscometer (rheometer) within a range of temperature and covering a specific range of shear rate.

Pipeline Restart Pressure Simulation

Measurement of gel strength (or yield stress) is extremely important for crude samples since they behave like a pseudoplastic Bingham fluid at very low temperatures. The gel strength of crude can be measured using rotational viscometer but there are some set back to it unless repeated tests are performed to confirm the results. There are many factors influencing it reliability. However, another reliable method is via a "Small Bore Model Pipeline" or slim tube test by measuring the Restart pressure of the crude sample.

In the event of a pipeline shutdown, the system will eventually cool to seabed temperature. In many cases this will result in wax crystallization within the fluid and in some cases, gel formation. It is necessary to be aware of pressure required to break the gel and restart the flow in such an eventuality. For this purpose, a model pipeline is used for 
static gel strength measurement. The principle of the method is the linear relationship between the force required to restart a model pipeline and the energy needed to restart a full-scale pipeline. Under controlled temperature conditions the pressure increase measured before oil starts to flow from the model pipeline is proportional to the pressure required to get oil flowing from a full-scale pipeline at the same temperature, the cooling rate and the length of the time held at the static temperature.

\section{Pour Point Depressant (PPD) Testing}

PPDs are used extensively to modify the crystallinity of hard waxes and to reduce the natural pour point of crude. The best PPD chemical and best dosage for crude oil treatment will be chosen based on the laboratory test results to:

Reduce pour point of crude oil;

Reduce viscosity of crude oil;

Improve rheological properties of crude oil;

Reduce wax deposition rate and pipeline restart pressure.

\section{Equipment And Test Procedures Used For Analyses}

\section{Pour Point Measurement}

The determination of pour point temperature can be conducted by different ways. The pour point temperature of blank sample (the mixture of $\mathrm{H} 1, \mathrm{H} 4$ and $\mathrm{H} 5$ ) and treated sample (rundown sample) are determined by using apparatus in full compliance with Standard Test Methods ASTM D-97.



Figure 1. Apparatus for Pour Point Test

Wax Appearance and Disappearance Temperatures measurement

The Wax Appearance Temperature is the temperature at which wax crystals begin to form or precipitate from the solution. Energy is released and is shown on the Differential Scanning Calorimeter (DSC) scan by the increase of the curve.

For WAT determination, the temperature will start at a point higher than the predicted WDT of the sample for the samples to completely melted. The temperature will typically decrease at a rate of $10 \mathrm{oC} / \mathrm{min}$ to a point where the sample is no longer pouring. A standard temperature range is from $100 \mathrm{oC}$ to $40 \mathrm{oC}$.

After run is completed, software will be used to calculate the Peak Area, including the Peak height. Set the endpoints at the base of the actual curve. This curve will occur over the complete run. When the run is complete, the WAT and WDT are determined based upon the tangential of the curve.

The state of the art DSC Instrument Model Q2000 of TA Instrument Company is used in laboratory for WAT and WDT of crude oil testing.

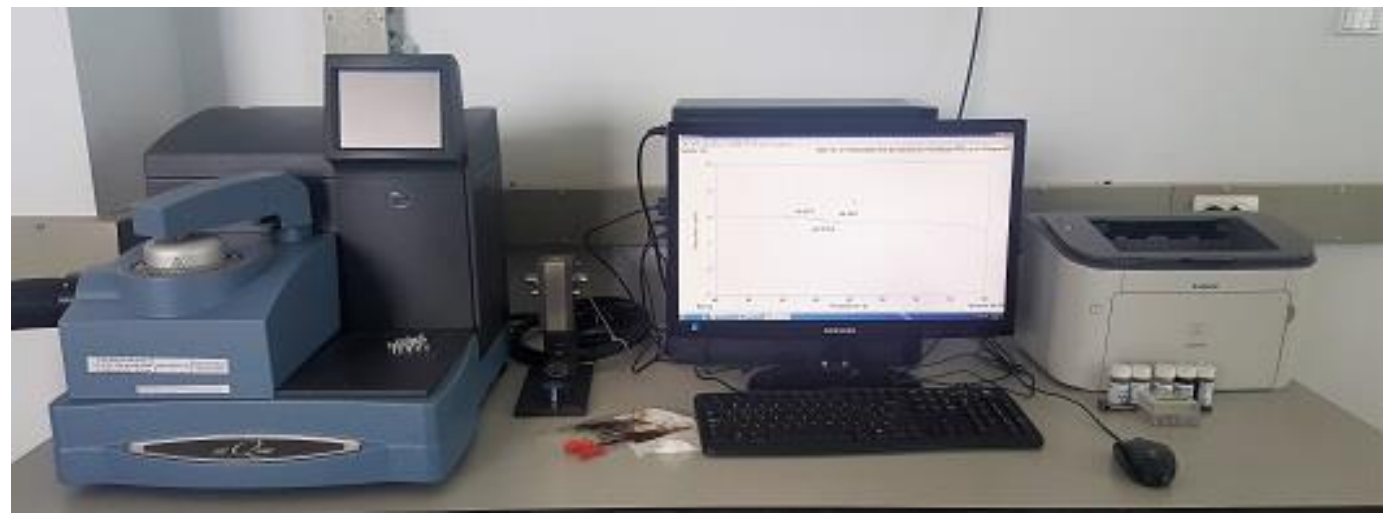

Figure 2. DSC Instrument Model Q2000 of TA Instrument Company 


\section{Wax Deposition Rate Measurement}

To measure the rate of wax deposition on the walls of a pipeline, the Dynamic Coaxial Deposition cell (Cold Finger) can be used. The dynamic coaxial cell allows simulate the flowing conditions in the pipeline by applying a shear to the cold finger surface where deposition occurs. The deposit accumulated on the cold surface, loosely referred to as "wax", contains normal paraffin, resins, gums and asphaltene as well as associated liquid oil.
The Coaxial cell consists of a stainless-steel cylinder, which is cooled internally by pumping cold liquid from the water bath. An outer heating jacket on the oil container maintains the bulk oil temperature. The shear is applied to the cold finger surface by rotating the outer cylinder at a controlled rate to simulate a shear rate provided by flowing liquid in the actual pipeline.

The wax crystals and other solid materials deposited on the cold surface were mechanical removed and weighed later.

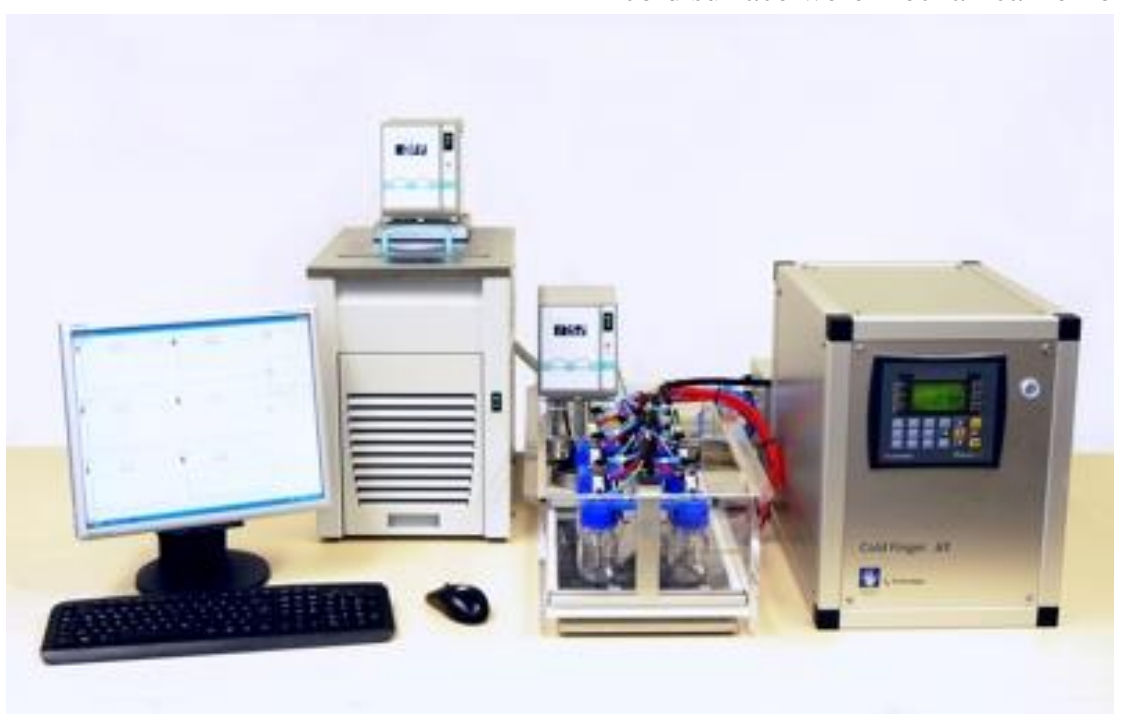

Figure 3. The Dynamic Coaxial Deposition cell (Cold Finger)

Measurement of wax deposition rate is carried out under dynamic conditions. A Cold-finger tube is immersed in an oil bath held at a temperature of $10 \mathrm{oC}$ above the cold finger tube temperature (this represent a delta Temp of $100 \mathrm{C}$ between the surface/wall of the pipe and the bulk of fluid in pipeline). In some case, the sea bed temperature can be used to set for the Cold Finger Temperature. The amount of wax deposited on the cold surface of known surface area is recorded over a specified time. The temperature of oil is then reduced to subsequent test temperature until the final test temperature, which is above the pour point of the crude. The wax deposition rate is measured as $\mathrm{g} / \mathrm{cm} 2 / \mathrm{hr}$ and the data will be expressed as $\mathrm{kg} / \mathrm{m} 2 /$ day.

\section{Viscosity and Dynamic Gel Strength Measurements}

The main equipment used for rheological studies are viscometer VT-550 made by Haake, Germany which consists of:

- $\quad$ Rotovisco RV-20, VT-550 ;

- Measuring system;

- Rheocontroller;

- Computer with software for control of testing process;

- Different standard rotors and cups.

- Circulating heating - cooling bath.

- Equipment compliance

As known, at present a common procedure for studying the rheological properties of waxy crude that can be applicable widely to all Oil Companies does not exist. The proposed procedures based on the results of analysis and generalization of experiences, procedures of Russian, Shell and BP laboratories, and instructions from viscometer manufacturer, Haake.

The dynamic viscosity and yield stress tests of crude oils are conducted as follows:

Heat up the sample container with the sensor system of Viscometer to start test temperature to $80 \mathrm{oC}$. The oil samples were transferred from the glass bottle to measuring cup of sensor system MV of viscometer Rotovisco VT-550 at initial temperature. The initial test temperature of samples was kept for $10 \mathrm{~min}$ at maximum shear rate of $150 \mathrm{~s}-1$ for crude oil and then the oil sample in sensor system was cooled down with cooling rate of $0.15 \mathrm{oC} / \mathrm{min}$ at constant shear rate of $20 \mathrm{~s}$ 1. The test procedure of crude oil then continues until reaching minimum seabed temperature of $210 C$.

For Yield Stress measurement, the shut-in time of 100 mins, 1000 mins, 2 days have been chosen.

Pipeline Restart Pressure Simulation

To study the effects of sedimentation of waxes, paraffins and asphaltenes during oil transport in pipelines, an amount of sample is pumped through a test line. If the wall temperature decreases below the WAT of the sample, wax sedimentations will form in the line.

After longer periods of standstill in the line (certain shut-in time), wax sedimentations can completely plug the line. At restarting the flow a high pressure can build up behind the pump, before the oil starts flowing again. Four capillary tubes with length of: $1.5 \mathrm{~m}, 5 \mathrm{~m}, 10 \mathrm{~m}$ and $15 \mathrm{~m}$ can be used. The brand-new Restart Loop from PSL company (Germany) 


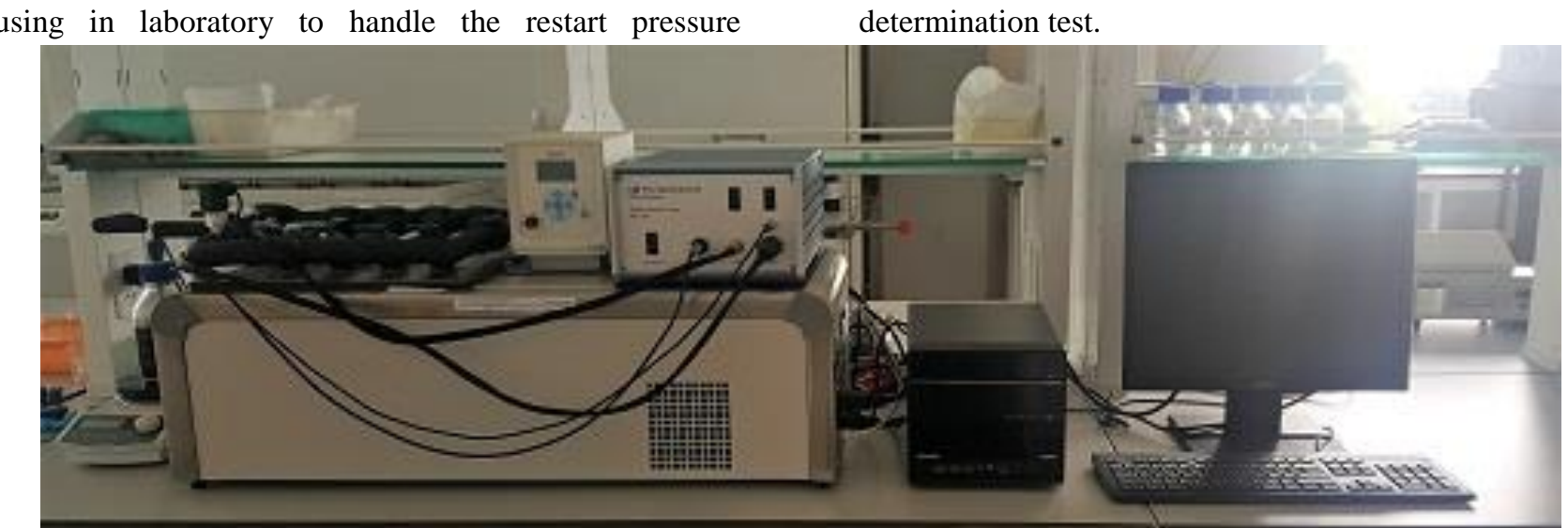

Figure 4. The brand-new Restart Loop from PSL company (Germany)

Crude oil sample is heated to above the WDT $(65-70 \mathrm{oC})$ or to the process temperature before the crude enters the low ambient temperature environment and circulated through the model pipeline.

The oil is circulated through the model pipeline in the coolant-bath at the same temperature as the oil. A minimum of 5 volumes of oil is passed through the model pipeline. If the multi-loop pipeline is used each line must be filled and circulated separately.

The pipeline is placed in a coolant bath, usually water, bath and the water cooled under controlled conditions using a programmable cooler. The cooling rate must mimic the rate experienced by the oil in the pipeline to be evaluated.

Once the minimum ambient temperature has been achieved the shut-in periods are measured. After each period has elapsed the pipelines can be isolated and restarted individually by pumping hot oil through the line.

Restart pressures are measured after time periods of 100 , 1000 minutes and 2 days at the minimum temperature. The purpose of the different time lapses is to find the maximum pressure required to "start" the model line.

The maximum pressure increase is measured and recorded. The base pressure required to keep the pipeline flowing is also recorded.

Yield stress/Gel strength of crude oil in pipeline is calculated by formulation (Perkins and Turner (1971)):

$$
\tau=\frac{D \cdot \Delta P}{4 \cdot L}
$$

Where: $\boldsymbol{\tau}$-gel strength/yield stress, Pa;

$\mathrm{D}$ - Inner Diameter of bore pipeline, $\mathrm{m}$;

$\Delta P \quad-\quad$ Restart Pressure/Differential
Pressure, bar;

$$
\text { L - Length of pipeline, } \mathrm{m} \text {; }
$$

\section{Test Results}

To prepare the blank crude oil sample, based on the actual production rates of $\mathrm{H} 1, \mathrm{H} 4$ and $\mathrm{H} 5$ (10876 bbls, $7166 \mathrm{bbls}$, 5083 bbls), H1, H4 and H5 samples have been mixed by the ratio of 2.1:1.4:1.0.

\section{Pour Point}

Pour points of blank and treated samples are as following:

Table 1. Pour points of blank and treated samples

\begin{tabular}{|l|l|}
\hline Sample & $\begin{array}{l}\text { Pour Point, oC (by ASTM } \\
\text { D5853) }\end{array}$ \\
\hline Blank sample & 27 \\
\hline Treated sample & 21 \\
\hline
\end{tabular}

\section{WAT and WDT}

The WAT of blank sample (by DSC) is $48.37 \mathrm{oC}$ while its WDT is $63.37 \mathrm{oC}$.

\section{Dynamic Viscosity}

Viscosity of blank sample is very high at temperatures closed to or lower than their pour points. At $21 \mathrm{oC}$ the viscosity of blank sample is about $1600 \mathrm{mPa}$.s. Viscosity of treated sample remains low at $210 \mathrm{C}$. For reference, the viscosity profiles of blank and treated samples are presented in Figure 5. 
“The Chemical Performance Evaluation for Pour Point Depressant (PPD) Testing, X Oil Field, Vietnam”

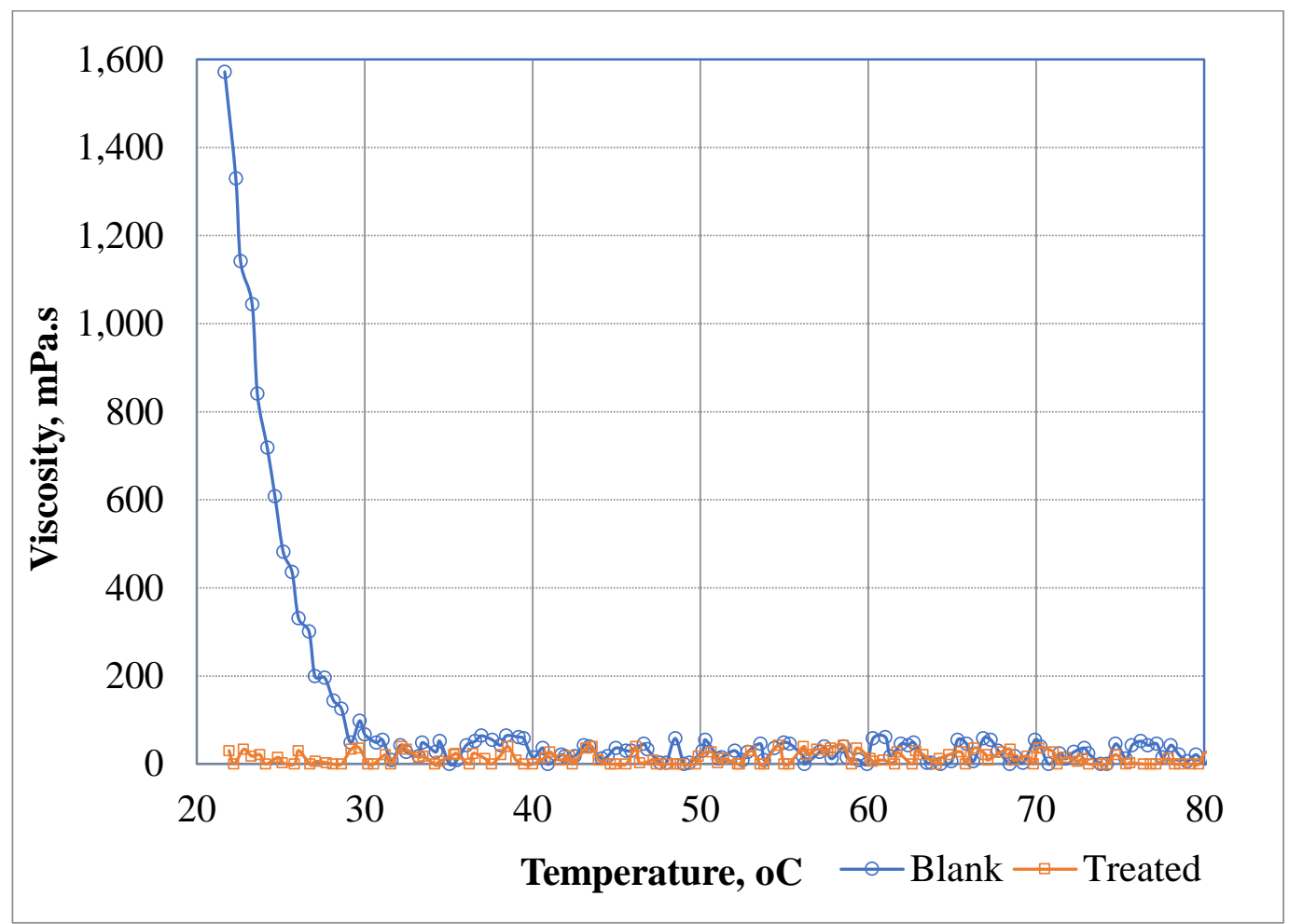

Figure 5. Viscosity profiles of blank sample and treated sample

From the figure of viscosity profiles visually can see the difference between the blank sample and the sample, treated by PPD.
Gel Strength/Yield Stress by Rheometer

Gel strength of blank sample and treated samples profiles are presented in Figure 6 and Figure7, which is as following:

Table 2. Gel strength of blank sample and treated samples

\begin{tabular}{|l|l|l|l|}
\hline Gel strength, $\mathrm{Pa}$ & Shut-in: 100 mins & Shut-in: 1000 mins & Shut-in: 2 days \\
\hline Blank & 123.7 & 146.0 & 181.0 \\
\hline Treated & 2.40 & 3.01 & 4.48 \\
\hline
\end{tabular}

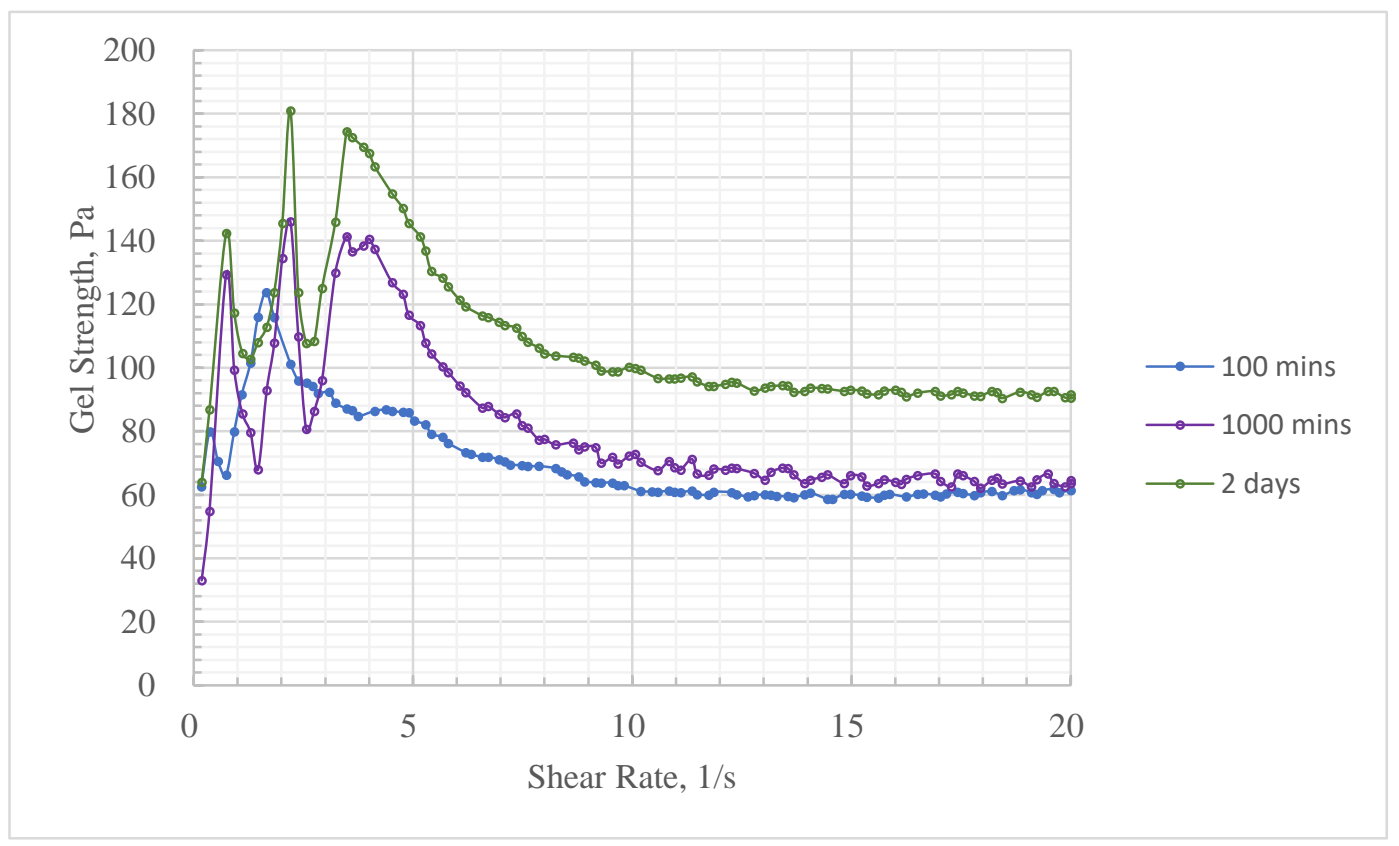

Figure 6. Gel strength of blank sample vs. shear rate 


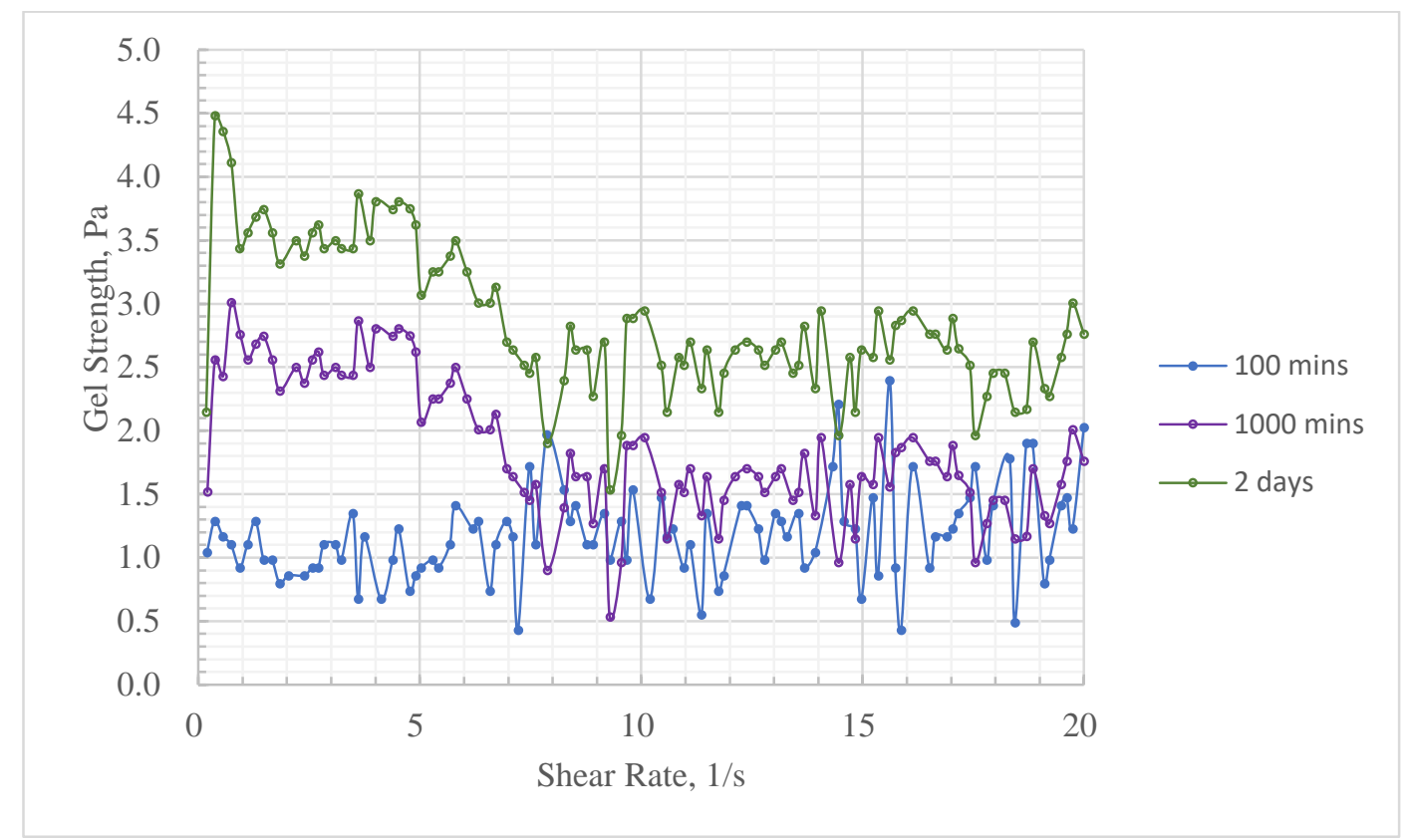

Figure 7. Gel strength of treated sample vs. shear rate

\section{Wax Deposition Rate by Cold Finger}

The wax deposition rate of blank and treated samples are as following:

Table 3. The wax deposition rate of blank and treated samples

\begin{tabular}{|l|l|l|l|l|}
\hline & T finger, oC & T oil, oC & Weight, $\mathrm{kg} / \mathrm{m} 2 /$ day & Protection, \% \\
\hline \multirow{3}{*}{ Blank } & 21 & 52 & 1.717 & N/A \\
\cline { 2 - 5 } & 42 & 52 & 0.527 & N/A \\
\hline \multirow{3}{*}{ Treated } & 21 & 52 & 1.551 & 9.67 \\
\cline { 2 - 5 } & 42 & 52 & 0.0002 & 99.96 \\
\hline
\end{tabular}

The results of wax deposition rate determination show that wax deposition rate of blank sample is high (at $210 \mathrm{C}$ might reach $1.717 \mathrm{~kg} / \mathrm{m} 2 /$ day). Treated sample also shows high wax deposition rate at $21 \mathrm{oC}(1.551 \mathrm{~kg} / \mathrm{m} 2 /$ day $)$. But at $42 \mathrm{oC}$, treatment by PPD shows good effect on reducing the rate of wax deposition (99.96\% protection).

Restart Pressure by Restart Loop

Pipeline restarts behaviors of blank and treated samples are as following:

Table 4. Pipeline restarts behaviors of blank and treated samples

\begin{tabular}{|l|l|l|l|l|}
\hline & $\begin{array}{l}\text { Pipeline length: L=5500mm; } \\
\text { ID=5.3mm }\end{array}$ & 100 mins & 1000 mins & 2 days \\
\hline \multirow{2}{*}{ Blank sample } & Max. diff pressure, bar & 4.07 & 1.84 & 1.4 \\
\cline { 2 - 5 } & Yield Stress, Pa & 53.93 & 48.76 & 123.67 \\
\hline \multirow{2}{*}{ Treated sample } & Max. diff pressure, bar & 1.37 & 0.44 & 0.51 \\
\cline { 2 - 5 } & Yield Stress, Pa & 18.15 & 11.66 & 45.05 \\
\hline
\end{tabular}

To have an overview of the change of differential pressure during restart pressure test for blank and treated samples, the following figures will inform the differential pressure values during the test (Figure 8): 
"The Chemical Performance Evaluation for Pour Point Depressant (PPD) Testing, X Oil Field, Vietnam"

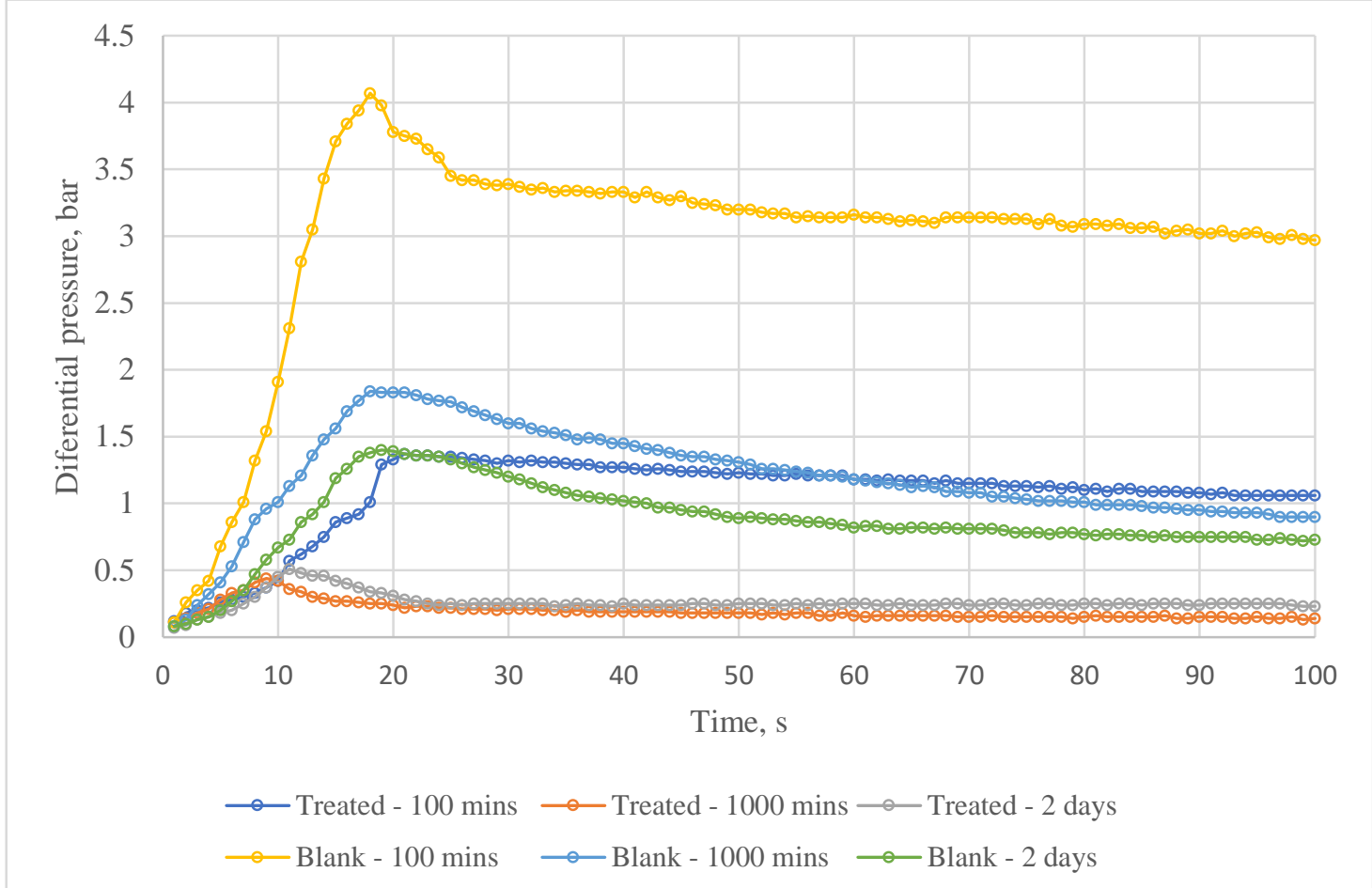

Figure 8. Differential Pressure vs. time after shut-in times

\section{CONCLUSIONS}

Treated crude oil sample (X rundown oil) shows the better rheology properties than Blank sample (the mixture of $\mathrm{H} 1$, $\mathrm{H} 4$ and H5), including:

Reducing pour point of blank sample;

Reducing viscosity of blank sample at low temperature range;

Reducing wax deposition rate of blank sample;

Reducing restart pressure/yield stress of blank samples.

\section{REFERENCE}

1. ASTM D97 - 17, Standard Test Method for Pour Point of Petroleum Products, Copyright ASTM International, 100 Barr Harbor Drive, West Conshohocken, PA 19428, USA, pursuant to license with ASTM International

2. J.R. Becker, Crude Oil Waxes, Emulsions and Asphaltenes, PennWell Books, 1997.

3. C. Chang, D. V. Boger, Q. D. Nguyen, "The yielding of waxy crude oils". Ind. Eng. Chem. Res. 37, 1998.

4. C. J. Dimitriou, G. H. McKinley, R. Venkatesan, "Rheo-PIV analysis of the yielding and flow of model waxy crude oils". Energy Fuels 25(7), 2011.

5. Ekaputra, A. et al. Impacts of Viscosity, Density and Pour Point to the Wax Deposition. Journal of Applied Sciences, v. 14, n. 23, 2014. 